\title{
Structural, morphological and optical properties of sol gel processed CdZnO nanostructured films: effect of precursor solvents
}

\author{
Amritpal Singh ${ }^{1}$ and Praveen Kumar ${ }^{2^{*}}$
}

\begin{abstract}
Cadmium-doped zinc oxide (CZO) has been the potential candidate for the fabrication of low-cost transparent conductors having applications in energy conversion devices such as thin-film solar cells and light-emitting diodes. In this work, the effect of different precursor solvents on the structural, morphological, and optical properties of sol-gel spin-coated CZO films was investigated. The X-ray diffraction study has revealed the hexagonal wurtzite crystal structure with crystallite size ranging from 45 to $49 \mathrm{~nm}$ for these films. The surface morphology of these films was analyzed by the atomic force microscopy. The precursor solvent effect was also analyzed using the UV-vis spectroscopy and fluorescence spectroscopic techniques. All the prepared films show the larger values of optical transparency (>80\%) along with the shift in the fundamental absorption edge and the direct optical gap was found to be between 3.14 and $3.19 \mathrm{eV}$. The highly intense band edge emission for the sample was synthesized using the 2-ethoxyethanol while the presence of other defect-related bands in the other samples has been observed. The change in the precursor solvent volatility influences the crystal structure to favor the change in the density/type of defect states in the bandgap is used to discuss the present results. The formation of highly porous films will be suitable for gas sensor applications while the larger value of optical transparency and lower surface roughness have their probable application as the transparent electrodes in optoelectronics.
\end{abstract}

Keywords: CdZnO films; Spin coating; XRD; UV-vis spectroscopy; Fluorescence spectroscopy

\section{Background}

Zinc oxide $(\mathrm{ZnO})$ is a II-VI compound semiconductor with a stable wurtzite structure and a direct wide bandgap $(3.37 \mathrm{eV})$ [1]. It has attracted intensive research effort for its unique optical and electrical properties, and versatile applications in ultraviolet light emitters, transparent electronics, piezoelectric devices, chemical sensors, spin electronics, and thin film transistors [2,3]. $\mathrm{ZnO}$ is commercially available with advantages such as comparatively low cost, environment-friendly non-toxic nature, high resistance to radiation damage, and high thermal and chemical stability. Generally, various dopants such as $\mathrm{Al}, \mathrm{Cd}, \mathrm{In}, \mathrm{K}, \mathrm{Mg}$, etc. have been used for improving the figure of merit (optimized value of optical gap and electrical conductivity) of the $\mathrm{ZnO}$ to be used as a potential TCO material in optoelectronics [4-6]. The

\footnotetext{
*Correspondence: prafiziks@gmail.com

${ }^{2}$ Department of Physics, DAV University, Sarmastpur, Jalandhar, 144301, India Full list of author information is available at the end of the article
}

cadmium $(\mathrm{Cd})$ is a material of interest as it reduces the bandgap of $\mathrm{ZnO}$ with an improvement in other useful properties. There are also a number of methods used to deposit $\mathrm{ZnCdO}$ thin films such as molecular beam epitaxy [7], pulse laser deposition (PLD) [8], metal organic chemical vapor deposition (MOCVD) [9], electrochemical deposition [10], DC reactive magnetron sputtering [11], spray pyrolysis method [12], and RF magnetron sputtering [13], but the sol-gel spin coating process is most widely used because of its simplicity and low cost [14].

There has been a lot of literature available in which $\mathrm{ZnCdO}$ thin films with varying composition of cadmium has been prepared $[2,4,12,15-17]$. In the literature, the different solvents have been reported for the sol-gel synthesis of various metal oxide films, but the detailed study for the CdZnO system have not been reported till today. Therefore, we have planned a systematic study for revealing the precursor solvent effect on the various physical properties such as structure, morphology, and 
optical properties of the spin-coated CZO films by X-ray diffraction (XRD), atomic force microscopy (AFM), and optical and fluorescence techniques.

\section{Methods}

The $\mathrm{Cd}_{0.1} \mathrm{Zn}_{0.9} \mathrm{O}$ thin films were deposited on silica glass substrates by sol-gel route. The precursor chemicals such as zinc acetate dihydrate $\left[\mathrm{Zn}\left(\mathrm{CH}_{3} \mathrm{COO}\right)_{2} \cdot 2 \mathrm{H}_{2} \mathrm{O}, \mathrm{CDH}\right.$, 99.5\%] and cadmium acetate dihydrate [Cd $\left(\mathrm{CH}_{3} \mathrm{COO}\right)$ $\left.{ }_{2} \cdot 2 \mathrm{H}_{2} \mathrm{O}, \mathrm{SDFCI}, 98 \%\right]$ were used. The different precursor solvents such as methanol, ethanol, isopropyl alcohol, and 2-ethoxyethanol were used in the present work. The ethanolamine $\left[\mathrm{C}_{2} \mathrm{H}_{7} \mathrm{NO}\right.$, Fisher Scientific, $98 \%$ pure] was used as a sol stabilizer. To deposit the $\mathrm{Cd}_{0.1} \mathrm{Zn}_{0.9} \mathrm{O}$ films, the calculated amounts for the precursor solution of $0.2 \mathrm{M}$ of zinc acetate dihydrate and cadmium acetate dihydrate was mixed in a solvent with continuous stirring for an hour at $60^{\circ} \mathrm{C}$. The sol stabilizer ethanolamine in 1:1 molar ratio was added in this solution and stirred for the next $1 \mathrm{~h}$ at $60^{\circ} \mathrm{C}$. The solution became transparent, clear, homogeneous, and stable at room temperature. This clear solution was kept undisturbed for $24 \mathrm{~h}$ for necessary hydrolysis process.

The aged sol was finally spun coated at 3,000 rpm for $60 \mathrm{~s}$ by putting few drops on the well-cleaned silica glass substrates. Thereafter, the films were dried after each coating at preheating temperature (approximately $250^{\circ} \mathrm{C}$ ) in a hot air oven for $2 \mathrm{~min}$. This process was repeated 15 times to obtain the required dense film of appropriate thickness. The prepared thin films were then annealed at $600^{\circ} \mathrm{C}$ with the help of muffle furnace in the air ambient for $1 \mathrm{~h}$.

The crystal phase structure was analyzed with an X'Pert PRO diffractometer (PANalytical GmbH, Kassel, Germany) equipped with a Giono-meter PW3050/60 working with $\mathrm{Cu} \mathrm{K}_{\alpha}$ radiation (1.54060 $\AA$ ). The surface morphology of the films was analyzed in contact mode by using atomic force microscope (Model: Solver Pro-M4, SPM, NT-MDT, Russia). The optical transmittance spectrum was recorded with the help of UV-vis spectrophotometer (Evolution 300, Thermo Scientific, Waltham, MA, USA). The 310-nm line of the 150-W xenon arc lamp was used to record the photoluminescence spectra using the spectrofluorometer (Lambda 45, Perkin Elmer, Waltham, MA, USA).

\section{Results and discussion Microstructure}

Figure 1 shows the X-ray diffraction patterns for the CZO film samples prepared with different precursor solvents are named as CZO-1 (methanol), CZO-2 (ethanol), CZO-3 (isopropanol), and CZO-4 (2-ethoxyethanol). Three prominent diffraction peaks viz. (100), (002), and (101) for the wurtzite-structured $\mathrm{ZnO}$ phase has been observed. The presence of prominent diffraction peaks reveal the polycrystalline nature of the films and no new peaks related to the cubic phase of $\mathrm{CdO}$ show that the

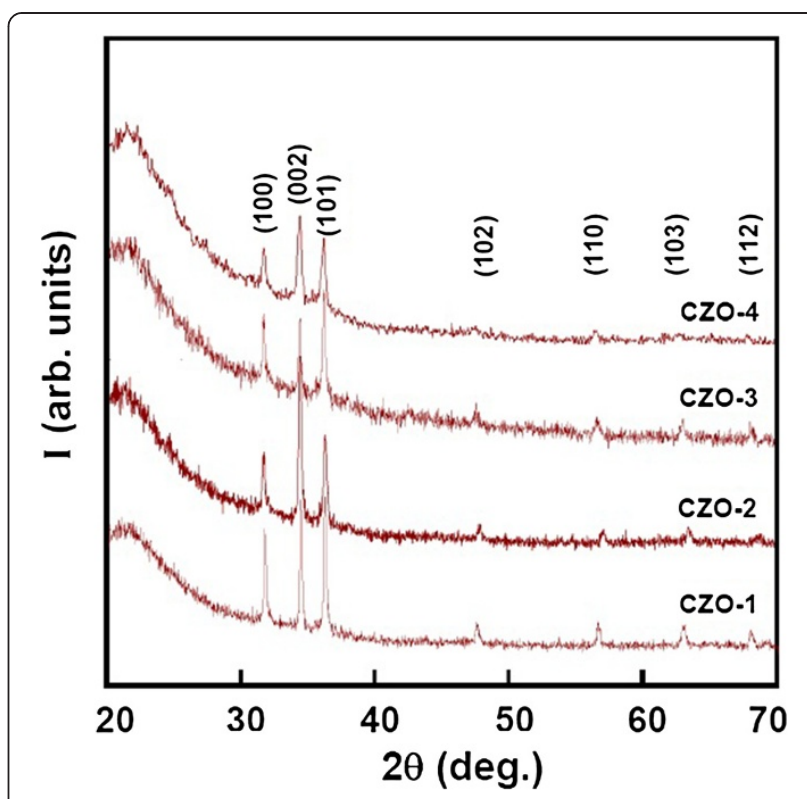

Figure 1 XRD patterns for the sol-gel-synthesized $\mathrm{Zn}_{0.9} \mathrm{Cd}_{0.1} \mathrm{O}$ films with different solvents.

incorporation of cadmium does not affect the wurtzite phase of $\mathrm{ZnO}$. This observation suggests that the films do not have any phase segregation or secondary phase formation. The relatively dominant diffraction (002) peak along with low-intensity (100) and (101) peaks has been observed for samples CZO-2 and CZO-4 samples. While, the intensity of the major diffraction peaks are approximately similar indicating a random orientation of crystallites in the CZO-1 and CZO-3 samples. It has also been reported that the volatile nature of the solvent affects the growth due to the immediate formation of vapors as well as the intermediate pyrolytic reactions for indium-doped zinc oxide films by spray pyrolysis technique [18]. In our case, the higher volatility results in the formation of dry layers of sols immediately in the coating process while the lesser volatile solvent takes longer times for the formation of the dry layer or might be formed during the preheating process. Therefore, the time taken for the formation of dry layers will possibly affect the crystal structure and surface morphology of the spin-coated films. The peak position along with the full width at half maximum (FWHM) values for diffraction peak (002) is summarized in Table 1. The similar results were also reported by others $[19,20]$.

The lattice constants ' $a$ ' and ' $c$ ' of the wurtzite structure can be calculated using the relations (1) and (2) as given below [19,21]:

$$
a=\frac{2}{\sqrt{3}} d_{002}
$$


Table 1 Values of peak position, fwhm value, lattice parameters, strain, crystallite size, grain size, surface roughness for CZO films

\begin{tabular}{llllllllll}
\hline Sample code & Solvent & $(\mathbf{2 \theta})_{\mathbf{0 0 2}}$ & $\boldsymbol{\beta}(\mathbf{r a d})$ & $\boldsymbol{c}(\AA)$ & $\boldsymbol{a}(\AA ̊)$ & $\boldsymbol{\varepsilon}\left(\times \mathbf{1 0}^{-\mathbf{5}}\right)$ & $\boldsymbol{D}_{\text {XRD }}(\mathbf{n m})$ & $\boldsymbol{D}_{\text {AFM }}(\mathbf{n m})$ & Sq $(\mathbf{n m})$ \\
\hline CZO-1 & Methanol & 34.32 & 0.0029 & 5.227 & 3.018 & 69.274 & 49.69 & 64.9 & 24.5 \\
CZO-2 & Ethanol & 34.38 & 0.0029 & 5.217 & 3.012 & 69.262 & 49.71 & 83.5 & 22.7 \\
CZO-3 & Isopropanol & 34.44 & 0.0032 & 5.208 & 3.007 & 76.414 & 45.20 & 68.2 & 22.7 \\
CZO-4 & 2-ethoxyethanol & 34.37 & 0.0029 & 5.219 & 3.013 & 69.264 & 49.70 & 50.7 & 15.1 \\
\hline
\end{tabular}

$$
c=2 d_{002}
$$

For the (002) plane, the calculated values of $a$ and $c$ lie between $a=3.007$ and $3.018 \AA$ and $c=5.208$ and 5.227 $\AA$ (JCPDS data card no. 36-1451). The crystallite size of the $\mathrm{Cd}_{0.1} \mathrm{Zn}_{0.9} \mathrm{O}$ films with different solvents was calculated using Scherer's formula [22]:

$$
D=0.9 \frac{\lambda}{\beta \cos \theta},
$$

where $D$ is the crystallite size, $\lambda$ is the wavelength of the X-ray (1.54059 $\AA$ ), $\beta$ is the broadening of diffraction line measured at the half of its maximum intensity in radians, and $\theta$ is the diffraction angle. The strain $(\varepsilon)$ along the $c$-axis for the samples was calculated by the following formula [20]:

$$
\epsilon=\frac{\beta \cos \theta}{4},
$$

where $\beta$ is full width at half maxima of the (002) peak. These calculated values of the strain along with the peak positions for (002) peaks are tabulated in Table 1. The peak position is shifted in accordance with the strain value, resulting in a variation in lattice constant $c$. The increase in the $c$ parameter clearly indicates that the smaller Zn ions (ionic radius $0.74 \AA$ ) are substituted by the larger $\mathrm{Cd}$ ions (ionic radius $0.97 \AA$ ) in the hexagonal wurtzite $\mathrm{ZnO}$ structure and hence there is an increase in lattice parameter $c$ values [23]. This increase in lattice constant $c$ leads to a decrease in diffraction angle $2 \theta$ for the (002) peak.

\section{Surface morphology}

Figure 2 shows the two-dimensional (2D) surface morphology of $\mathrm{Cd}_{0.1} \mathrm{Zn}_{0.9} \mathrm{O}$ thin films. From this, it is concluded that the films have uniformly distributed spherical or distorted spherical grains giving the smooth surface morphology. The deformed shaped grains have been observed for the CZO-1 and CZO-2 while nearly spherical grains were observed for the other two film samples. The calculated values of surface roughness and the grain sizes are summarized in Table 1. It has been observed that a minimum surface roughness has been found for the CZO-4 sample while the CZO-1 sample has the maximum value. Similarly, the smallest grains were found for the CZO-4 $(50.7 \mathrm{~nm})$ and largest for the CZO-2 (approximately $83.5 \mathrm{~nm}$ ) film samples. These grain size values are different from the crystallite size values obtained from the XRD analysis. This may be due to the reason that AFM measures the grain size on the sample surface only and a grain may contain several crystals aligned in the same direction, i.e., have same orientation, and two grains are separated by grain boundaries because of misalignment of the crystals by differing their orientation. However, XRD gives the crystallite size as the $\mathrm{X}$-rays determine the crystal structure by determining the close pack planes and distance between two atoms. In other words, one grain may contain sub-grains with the same alignment to form crystals with

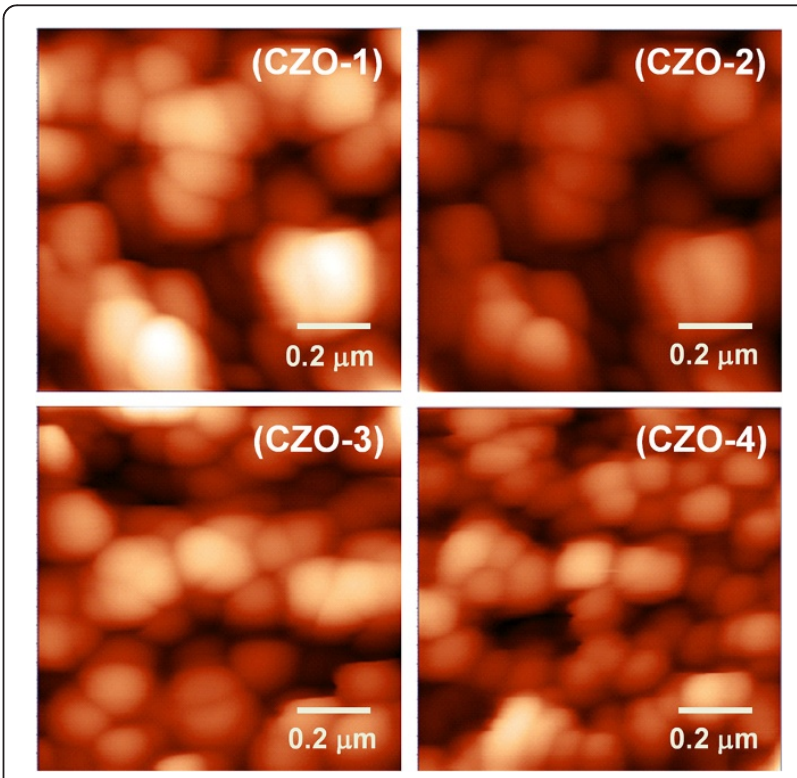

Figure 2 AFM images for CZO (1-4) samples with solvents methanol, ethanol, isopropanol and 2-ethoxy ethanol respectively. 
larger crystallite size. The wide variation in the surface morphology and grain sizes reveal the importance of the precursor solvents in the synthesis of these film samples. This may be due to the different volatile nature of these alcohols; the solvent which is more volatile evaporates quickly during the spin coating process (solvent quenching effect) leaving randomly oriented grains on the surface. The lowest value of grain size (approximately $50.7 \mathrm{~nm}$ ) has been observed for the less volatile 2-ethoxyethanol solvent and the larger grain size (approximately $83.5 \mathrm{~nm}$ ) for the sample in the most volatile precursor solvent ethanol.

\section{Optical properties}

Figure 3 shows the optical transmission spectrum for the CZO films in the wavelength region of 200 to 1,100 $\mathrm{nm}$. The observation of interference fringes has its origin in the interference of light reflected between air-film and film-substrate interface. It is clear from the figure that all the samples exhibit interference fringes with an average transmission of more than $80 \%$ in the visible and NIR region, while the steepness of the absorption edge indicates the deposition of good quality films for CZO-4 sample.

The variation of the absorption coefficient $(\alpha)$ with the photon energy $(h v)$ is related by the relation as $[24,25]$ :

$$
\alpha h v=A\left(\left(h v-E_{\mathrm{g}}\right)^{\beta}\right)
$$

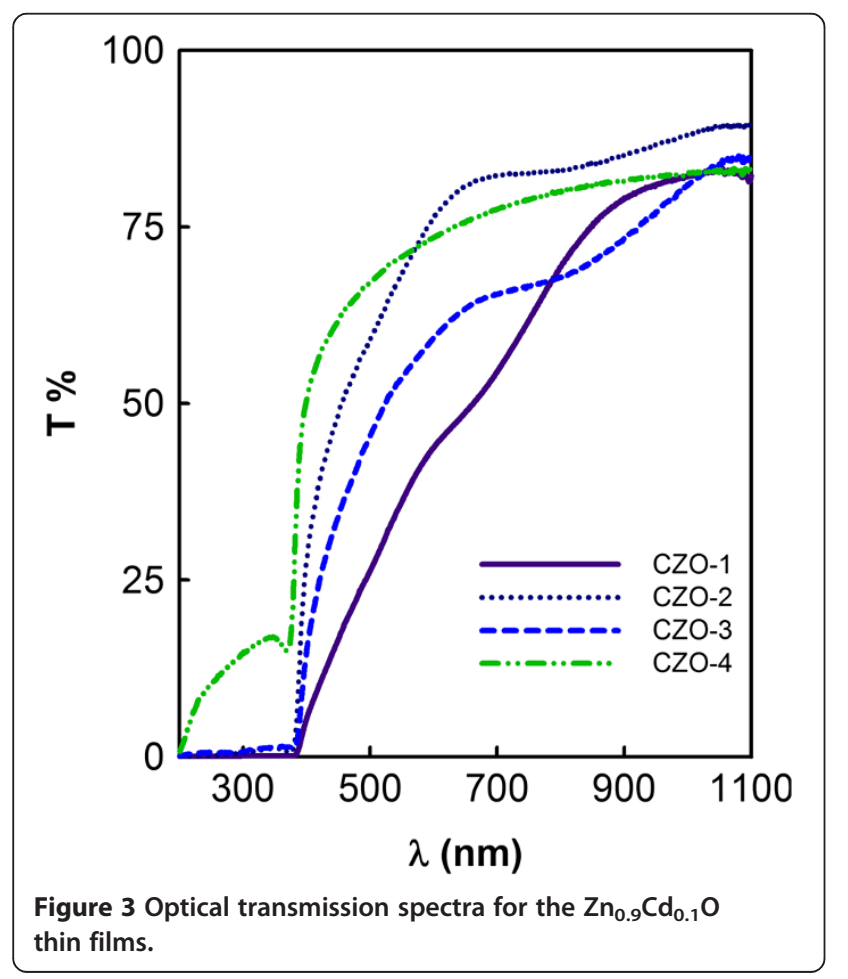

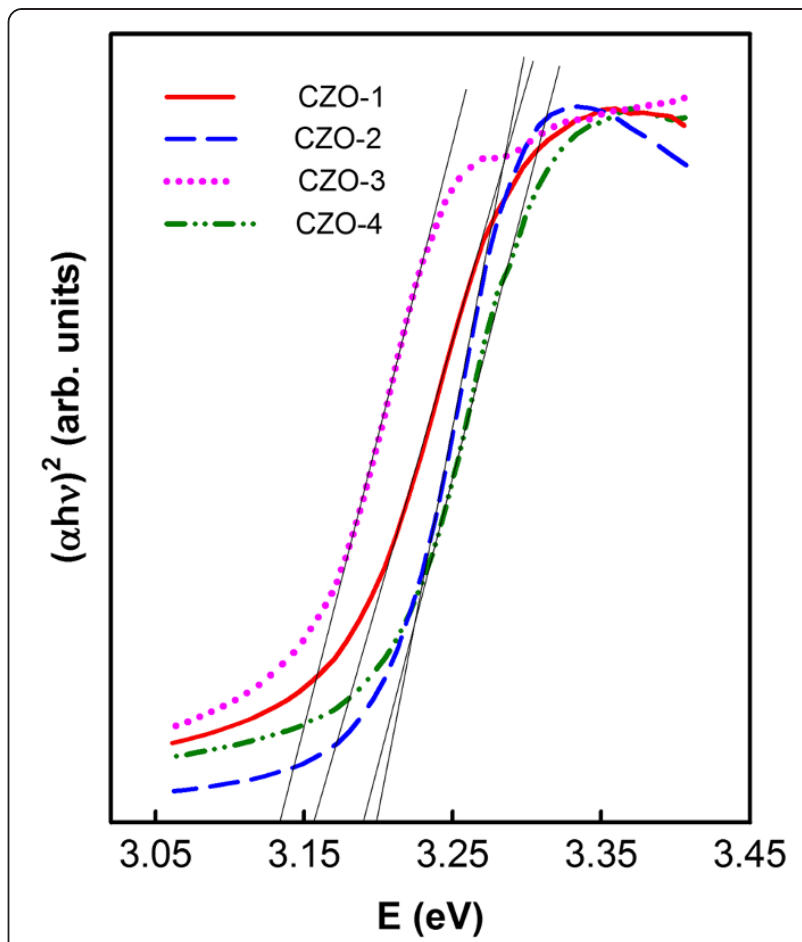

Figure 4 Variation of $(a h v)^{2}$ with photon energy $(h v)$ for $\mathrm{Zn}_{0.9} \mathrm{Cd}_{0.1} \mathrm{O}$ films deposited using different precursor solvents.

where $A$ is a constant, $E_{\mathrm{g}}$ is the optical gap and $\beta$ is the exponent whose value varies between $1 / 2$ to 2 and determines the nature of transitions, its value is taken as $1 / 2$ for the case of direct bandgap semiconductors (i.e., $\mathrm{ZnO}$ ). From Equation (5) follows that

$$
\left((\alpha h v)^{2}\right)=A\left(h v-E_{\mathrm{g}}\right)
$$

The variation of $(\alpha h v)^{2}$ versus photon energy $(h v)$ for all the CZO samples is shown in Figure 4. The energy

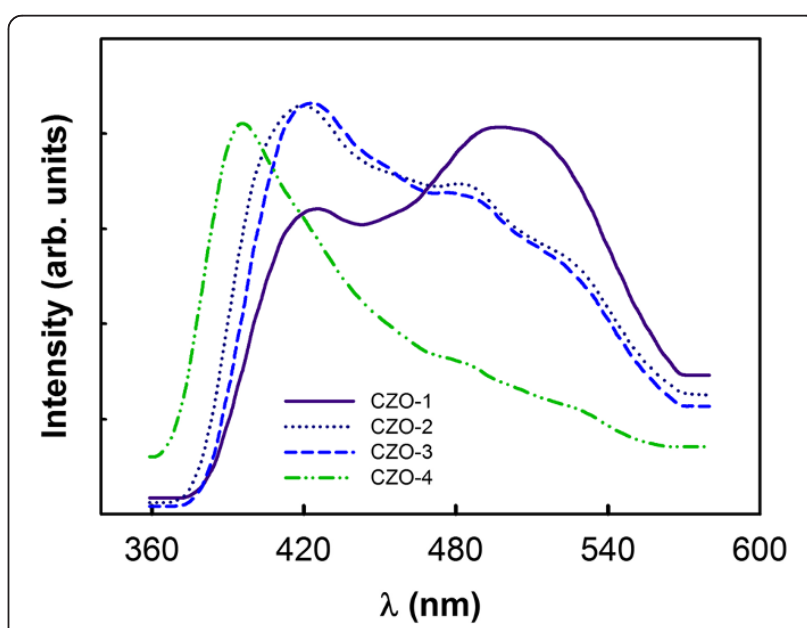

Figure 5 The emission spectra for $\mathrm{Zn}_{0.9} \mathrm{Cd}_{0.1} \mathrm{O}$ films at 310-nm excitation energy. 
gap $\left(E_{\mathrm{g}}\right)$ of the samples is evaluated from the intercept of the linear portion of each curve on the $x$-axis [25,26]. The optical gap for these films lies in the range 3.14 to $3.19 \mathrm{eV}$ with the lowest value for CZO-3 $(3.14 \mathrm{eV})$ and highest for CZO-2 $(3.19 \mathrm{eV})$. Thus, the use of different solvent affects the microstructure of the film network which causes the change in the optical properties of the films. Therefore, the large value of optical gap along with good transmittance for the CZO-4 sample makes it a better choice for application as transparent electrodes.

\section{Photoluminescence}

Figure 5 shows the emission spectra of the CZO films at 310-nm excitation energy. Three characteristic bands in the ultraviolet, blue, and green regions have been observed for all the samples. The dominant emission peak at $420 \mathrm{~nm}(\mathrm{CZO}-1$ to $\mathrm{CZO}-3)$ and $395 \mathrm{~nm}$ for the CZO4 generally termed as the near-band-edge emission (NBE) in wide direct bandgap transition of $\mathrm{ZnO}$ semiconductors for the recombination of free excitons through exciton-exciton collision process. Generally, the $\mathrm{ZnO}$ has the NBE band at $380 \mathrm{~nm}$ [27], and the shift in its position could also be related to the decrease in the optical gap energy in the Cd-doped $\mathrm{ZnO}$ films $[19,23]$. This emission in the UV region for the CZO- 4 confirms the formation of the highest quality crystal structure of the films with the 2-ethoxyethanol solvent. The increased intensity for 484and 521-nm bands as compared to the NBE emission has been observed for the CZO-1 film sample, which is attributed due to the deep-level defects such as zinc vacancy or oxygen vacancy/interstitials in $\mathrm{ZnO}$ and/or to the increase in the porosity of the film network, generally observed for the sol-gel-synthesized films [28]. As the NBE band is dominated by the defect-related band in the CZO-4, i.e., the films with the methanol solvent (highest volatile nature) have been observed. Therefore, this study also suggests us that the use of highly volatile solvents may also cause the increase in the porous structure of films and thus inducing the other structural defects in the band structure of the films. This suggests that the use of highly volatile solvents such as methanol cause the enhancement in these defects in the synthesized films. However, the small intensity of the latter two bands for CZO-2 and CZO-3 film samples could be due to the relatively lesser volatility of the ethanol and isopropyl alcohol used in the present case. Therefore, the samples made in methanol and isopropyl alcohol have lower bandgap as compared with the samples prepared in ethanol and 2-ethoxyethanol but these two samples (CZO-2 and CZO-4) have a better crystal structure which is being confirmed by the UV emission by these samples. The similar results were reported by others $[19,20,28]$.

\section{Conclusions}

We have studied the effect of four different solvents viz. methanol, ethanol, isopropyl alcohol, and 2-ethoxyethanol on the structure and optical properties of sol-gelsynthesized $\mathrm{Zn}_{0.9} \mathrm{Cd}_{0.1} \mathrm{O}$ thin films. The $\mathrm{XRD}$ result confirms the formation of a hexagonal wurtzite structure of $\mathrm{ZnO}$ without any trace peaks for the cubic $\mathrm{CdO}$ phase. The grain sizes of 45.2 to $49.71 \mathrm{~nm}$ and the lattice parameters $a$ (3.007 to $3.018 \AA$ ) and $c$ (5.208 to $5.227 \AA$ ) were calculated from the diffraction data. The higher value of the strain for the sample synthesized with the methanol while lowest for the isopropyl alcohol has been found. The AFM study shows the smooth surface morphology with the spherical structured along with some deformed grains crystallized on the surface of the films. The highest value of optical transparency for the sample with 2-ethoxyethanol solvent and the lowest for the sample with the methanol solvent has been observed. The optical gap is also found to change with the use of different solvents. The photoluminescence spectra exhibit the near-band-edge emission in the 395- to 424$\mathrm{nm}$ range along with the other two peaks centered at 484 and $521 \mathrm{~nm}$, respectively. The smaller value of the defects or the high quality of the crystal structure along with larger transmission for the sample prepared using the 2ethoxyethanol solvent could be best suited for their transparent electrode applications.

\section{Competing interests}

The authors declare that they have no competing interests.

\section{Authors' contributions}

AS performed the synthesis and take the necessary experimental data while PK supervised and prepared the manuscript. Both authors read and approved the final manuscript.

\section{Authors' information}

AS has been completed his B. Tech. (ECE) from Amritsar College of Engineering and Technology and M.Tech. (Nano Science \& Technology) form the DAV Institute of Engineering and Technology, Jalandhar. His main area of research is on $\mathrm{ZnO}$ based nanostructured coating for device applications. PK is presently working as Assistant Professor (Physics), DAV University,

Jalandhar. Prior to this, he is also worked at the Nanotechnology Research Centre, DAVIET, Jalandhar. He received his B. Sc. (NM) from the Himachal Pradesh University, Shimla, India and his M.Sc. (Applied Physics) from the GND University, Amritsar, India. He also got post-doctoral fellowships as SRF (extended) and as research associate from CSIR New Delhi for 3 years. He obtained his Ph.D. in the field of material science, some thermal, optical and structural characterization of chalcogenide semiconductors from the same institute. His current research interest includes synthesis and characterization of metal oxide semiconductors, polymer nanocomposites, chalcogenide thin films etc. He has more than 30 international journal publications to his credit.

\section{Acknowledgements}

The authors are thankful to Prof. R. Thangaraj and Dr. Kanchan L. Singh for their helpful suggestions. The authors are also expressing their sincere thanks to the Principal, DAVIET, Jalandhar for providing the necessary facilities for completing this work. Authors are thankful to Dr. Rajiv Kumar, DAV College, Jalandhar for providing UV-Vis Spectroscopy facility.

\section{Author details}

${ }^{1}$ Nanotechnology Research Centre, DAVIET, Kabir Nagar, Jalandhar 144008, India. ${ }^{2}$ Department of Physics, DAV University, Sarmastpur, Jalandhar 144301, India. 
Received: 30 January 2013 Accepted: 17 October 2013

Published: 14 Nov 2013

\section{References}

1. Tsay, CY, Fan, KS, Chen, CY, Wu, JM, Lei, CM: Effect of preheating process on crystallization and optical properties of sol-gel derived $\mathrm{ZnO}$ semiconductor thin films. J. Electroceram. 26, 23 (2011)

2. Lee, D, Kim, S, Lee, S: Zinc cadmium oxide thin film transistors fabricated at room temperature". Thin Solid Films 519, 4361 (2011)

3. Sonawane, BK, Shelke, V, Bhole, MP, Patil, DS: Structural, optical and electrical properties of cadmium zinc oxide films for light emitting devices. J. Phys. Chem. Solids 72, 1442 (2011)

4. Caglar, Y, Caglar, M, Ilican, S, Ates, A: Morphological, optical and electrical properties of $\mathrm{CdZnO}$ films prepared by sol-gel method. J. Phys. D: Appl. Phys. 42, 065421 (2009)

5. Duan, LB, Zhao, XR, Liu, JM, Geng, WC, Xie, HY, Sun, HN: Effect of annealing ambient on the structural, optical and electrical properties of (Mg, Al)codopedZnO thin films. Phys. Scr. 85, 035709 (2012)

6. Abadi, MR, Behdani, M, Arabshahi, H, Hosseini, N: Indium-doped zinc oxide thin films by sol-gel method. Int. Rev. Phys. 12, 3 (2009)

7. Sadovef, S, Blumstengel, S, Cui, J, Puls, J, Rogaschewski, S, Schafer, P: Visible band-gap $\mathrm{ZnCdO}$ heterostructures grown by molecular beam epitaxy. Appl. Phys. Lett. 89, 201907 (2006)

8. Kumar, V, Lethy, K, Kumar, A, Krishnan, R, Pillai, NV, Pillai, V, Philip, R: Effect of cadmium oxide incorporation on the microstructural and optical properties of pulsed laser deposited nano structured zinc oxide thin films. Mater. Chem. Phys. 121, 406 (2010)

9. Ye, JD, Gu, SL, Zhu, SM, Chen, T, Hu, LQ, Qin, F, Zhang, R, Shi, Y, Zheng, YD: The growth and annealing of single crystalline $\mathrm{ZnO}$ films by low-pressure MOCVD. J. Cryst. Growth 243(1), 151 (2002)

10. Singh, T, Pandya, DK, Singh, R: Synthesis of cadmium oxide doped ZnO nanostructures using electrochemical deposition. J. Alloys Compd. 509, 5095 (2011)

11. Ma, DW, Ye, ZZ, Huang, JY, Zhu, LP, Zhao, BH, He, JH: Effect of post annealing treatments on the properties of $\mathrm{Zn}_{1-x} \mathrm{Cd}_{x} \mathrm{O}$ films on glass substrates. Mater. Sci. Eng. B 461, 250 (2001)

12. Gandarilla, F, Morales-Acevedo, A, Vigil, O, Hesiquio-Garduño, V, Vaillant, L, Contreras-Puente, $\mathrm{V}$ : Micro-structural characterization of annealed cadmium-zinc oxide thin films obtained by spray pyrolysis. Mater. Chem. Phys. 78, 840 (2003)

13. Lee, JB, Kwak, SH, Kim, HJ: Effects of surface roughness of substrates on the c-axis preferred orientation of $\mathrm{ZnO}$ films deposited by r.f. magnetron sputtering. Thin Solid Films 423(2), 262 (2003)

14. Karyaoui, M, Jaballah, AB, Mechiak, R, Chtourou, $R$ : The porous nature of $\mathrm{ZnO}$ thin films deposited by sol-gel Spin-Coating technique. IOP Conf. Series: Mater. Sci. Engng. 28, 012019 (2012)

15. Ogawa, Y, Fujihara, S: Blue luminescence of $\mathrm{MgZnO}$ and $\mathrm{CdZnO}$ films deposited at low temperatures. J. Electrochem. Soc. 154, J283 (2007)

16. Choi, $Y$, Lee, $C$, Cho, S: Transparent conducting $\mathrm{Zn}_{1-x} \mathrm{Cd}_{x} \mathrm{O}$ thin films prepared by the sol-gel process. Thin Solid Films 289, 153 (1996)

17. Ilican, S, Caglar, Y, Caglar, M, Kundakci, M, Ates, A: Photovoltaic solar cell properties of $\mathrm{Cd}_{x} \mathrm{Zn}_{1-x} \mathrm{O}$ films prepared by sol-gel method. Int. J. Hydr. Ener. 34, 5201 (2009)

18. Maldonado, A, Luz Olvera, M, Guerra, S, Asomoza, R: Indium-doped zinc oxide thin films deposited by chemical spray starting from zinc acetylacetonate: effect of the alcohol and substrate temperature. Sol. Ener. Mater. Sol. Cells 82, 75 (2004)

19. Singh, A, Kumar, D, Khanna, P, Joshi, B, Kumar, M: Effect of post annealing temperature on structural and optical properties of $\mathrm{ZnCdO}$ thin films deposited by sol-gel method. Appl. Surf. Sci. 258, 1881 (2011)

20. Khan, Z, Khan, M, Zulfequar, M, Khan, M: Optical and structural properties of $\mathrm{ZnO}$ thin films fabricated by sol-gel method". Mater. Sci. Appl. 2, 340 (2011)

21. Khanlary, M, Isazadeh, S: Structural and optical properties of $\mathrm{ZnO}$ thin films prepared by sol gel method". Micro Nano Lett. 6(9), 767 (2011)

22. Muiva, CM, Sathiaraj, TS, Maabong, K: Effect of doping concentration on the properties of aluminium doped zinc oxide thin films prepared by spray pyrolysis for transparent electrode applications. Cer. Inter. 37, 555 (2011)

23. Vijayalakshmi, S, Venkataraj, S, Jayavel, R: Characterization of cadmium doped zinc oxide $(\mathrm{Cd}: \mathrm{ZnO})$ thin films prepared by spray pyrolysis method. J. Phys. D: Appl. Phys. 41, 245403 (2008)
24. Stenzel, O: The Physics of Thin Film Optical Spectra: An Introduction. Springer-Verlag, Heidelberg (2005)

25. Kaur, J, Kumar, P, Sathiaraj, TS, Thangaraj, R: Structural, optical and fluorescence properties of wet chemically synthesized $\mathrm{ZnO}: \mathrm{Pd}^{2+}$ nanocrystals. Int. Nano. Lett. 3, 4 (2013)

26. Shakti, N, Gupta, P: Structural and optical properties of sol-gel prepared ZnO thin film". Appl. Phys. Res. 2(1), 19 (2010)

27. Gayen, N, Sarkar, K, Hussain, S, Bhar, R, Pal, A: ZnO films prepared by modified sol-gel technique. Ind. J. Pure Appl. Phys. 49, 470 (2011)

28. Ghodsi, F, Absalan, $\mathrm{H}$ : Comparative study of $\mathrm{ZnO}$ thin films prepared by different sol-gel route". Acta Phys Pol. A 118(4), 659 (2010)

\subsection{6/2228-5326-3-57}

Cite this article as: Singh and Kumar: Structural, morphological and optical properties of sol gel processed $\mathrm{CdZnO}$ nanostructured films: effect of precursor solvents. International Nano Letters 2013, 3:57

\section{Submit your manuscript to a SpringerOpen ${ }^{\odot}$ journal and benefit from:}

- Convenient online submission

- Rigorous peer review

- Immediate publication on acceptance

- Open access: articles freely available online

- High visibility within the field

- Retaining the copyright to your article

Submit your next manuscript at $>$ springeropen.com 